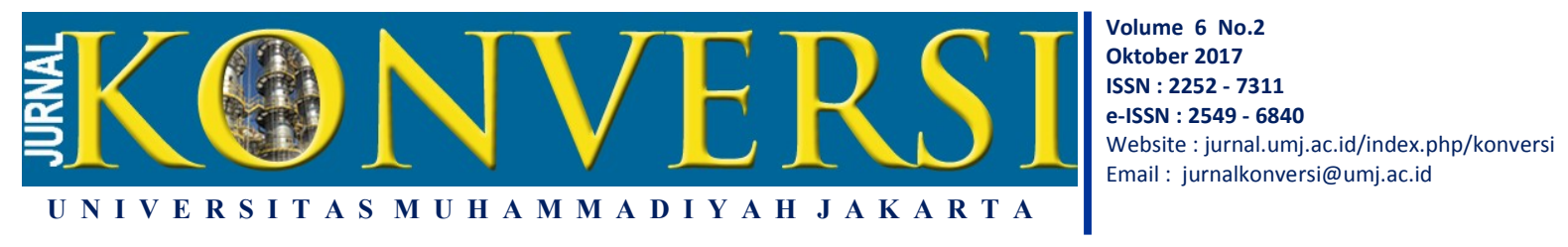

\title{
POTENSI PANAS BUMI DI KABUPATEN MANOKWARI SELATAN PROVINSI PAPUA BARAT BERDASARKAN ANALISA GEOKIMIA
}

\author{
Agustinus Denny Unggul Raharjo ${ }^{1}$, Nur Prasetyo Ponco Nugroho ${ }^{2}$, dan Hastowo \\ Resesiyanto ${ }^{3}$ \\ ${ }^{1}$ Jurusan Teknik Perminyakan Universitas Negeri Papua \\ a.raharjo@unipa.ac.id
}

\begin{abstract}
ABSTRAK
Kabupaten Manokwari Selatan merupakan daerah otonomi baru di Provinsi Papua Barat dengan potensi sumberdaya alam besar. Sebagai daerah pemekaran baru, kedepan akan mengalami pertambahan penduduk yang signifikan. Pertambahan penduduk bersama dengan pembangunan dan modernisasi akan membawa beban pada kebutuhan listrik, sebagai alternatif pemenuhan listrik dapat dengan cara memanfaatkan sumberdaya panasbumi yang terdapat di Kampung Demini, Distrik Momiwaren. Penelitian bertujuan mengetahui potensi sumberdaya panasbumi di Kampung Demini dengan menggunakan metode geothermometer untuk perkiraan suhu reservoir panasbumi berdasarkan kandungan $\mathrm{SiO}_{2}, \mathrm{Na}$, dan K. Berdasarkan hasil penelitian, walaupun berjenis suhu rendah, mata air panas Demini dapat dikembangkan menjadi pembangkit listrik siklus binari.
\end{abstract}

Kata kunci: Panasbumi, Siklus Binari, Kabupaten Manokwari Selatan

\begin{abstract}
South Manokwari Regency is a new autonomous region in West Papua Province with abundant natural resources. As new autonomous region the regency will experienced significant population growth. Population growth along with development and modernization will give burden to electricity demand. Alternatively, electricity could be acquired with geothermal resources in Demini vilage, Momiwaren District. The research aims to reveals the geothermal resources potent in Demini vilage using geothermometer method to predict the geothermal reservoir temperature. Based on survey the geothermal resources, altough lowenthalpy type, could be developed into binary cycle electric generator.
\end{abstract}

Keywords: Geothermal, Binary Cycle, South Manokwari Regency 


\section{PENDAHULUAN}

Kabupaten Manokwari Selatan merupakan kabupaten pemekaran baru di wilayah Provinsi Papua Barat. Justifikasi pemekaran daerah otonomi ini selain dari jumlah penduduk, potensi sumberdaya alam, juga karena kelancaran pelayanan administrasi publik. Sebagai daerah otonomi baru tentu banyak yang harus dibenahi dan dilakukan untuk dapat menyamai perkembangan di daerah induk maupun Kabupaten lain yang telah lebih dulu ada. Untuk mendukung pembangunan di Kabupaten Manokwari Selatan salah satu hal penting adalah terjaminnya ketersediaannya energi listrik.

Kondisi pada saat ini listrik di Kabupaten Manokwari Selatan bersumber pada Pembangkit Listrik Tenaga Diesel dan Pembangkit Listrik Tenaga Surya, itupun cakupannya terbatas ditinjau dari daerah layanan dan waktu layanan yang hanya 12 saja. Terlebih dengan perkembangan jumlah penduduk dan pembangunan pada sektor pertanian, pariwisata dan industri dimasa depan maka perlu melihat pula sumber-sumber energi listrik baru sebagai alternatif yang sudah ada.

Mengandalkan energi listrik dari bahan bakar fosil bukan merupakan hal yang bijak, untuk itu perlu kiranya melihat potensi energi baru terbarukan sebagai solusi sumber energi listrik di Kabupaten Manokwari Selatan. Salah satu potensi sumber energi yang dapat dimanfaatkan sebagai pembangkit listrik di Kabupaten Pegunungan Manokwari Selatan adalah sumber energi panasbumi. Berdasarkan survei pendahuluan pada tahun 2009 oleh Pusat Sumber Daya Geologi, Badan Geologi, Departemen Energi dan Sumber Daya Mineral, Kabupaten Manokwari Selatan memiliki potensi panasbumi di sekitar Kampung Demini, Distrik Momiwaren.

Penelitian yang dilakukan merupakan usaha verifikasi dari temuan terdahulu. Penelitian dilakukan secara survei lapangan dan uji sampel di laboratorium. Sampel yang akan diuji adalah sampel fluida panasbumi yang digunakan sebagai alat untuk menentukan panas di reservoir panasbumi dengan metode geothermometer.
Metode geothermometer merupakan metode pendugaan panas di reservoir dengan menggunakan hasil analisa geokimia fluida panasbumi yang ditemukan dipermukaan; berupa anion, kation dan kandungan silika. Analisa geokimia dilakukan di laboratorium geokimia Pusat Sumber Daya Mineral Batubara dan Panas Bumi, Kementerian Energi Sumber Daya Mineral, Bandung.

\section{METODOLOGI PENELITIAN}

Penelitian dilakukan melalui survei lapangan, pengambilan sampel fluida panasbumi, dan penentuan panas reservoir menggunakan metode geothermometer.

\section{Bahan dan Alat}

Bahan dan alat yang digunakan dalam survei lapangan dan pengambilan sampel fluida panasbumi adalah sebagai berikut (Gambar 1 dan Gambar 2):

- Peta lokasi

- Kompas geologi

- Parang

- GPS

- Palu geologi

- Meteran

- Kamera digital

- Thermometer digital

- $\mathrm{pH}$ meter digital

- Universal Indicator

- Clipboard

- Larutan $\mathrm{HCl}$

- $\mathrm{HNO}_{3}$ 1:1

- Syringe $50 \mathrm{ml}$

- Filter Syringe $0,45 \mu \mathrm{m}$

- Botol $500 \mathrm{ml}$

- Wadah PE $1500 \mathrm{ml}$

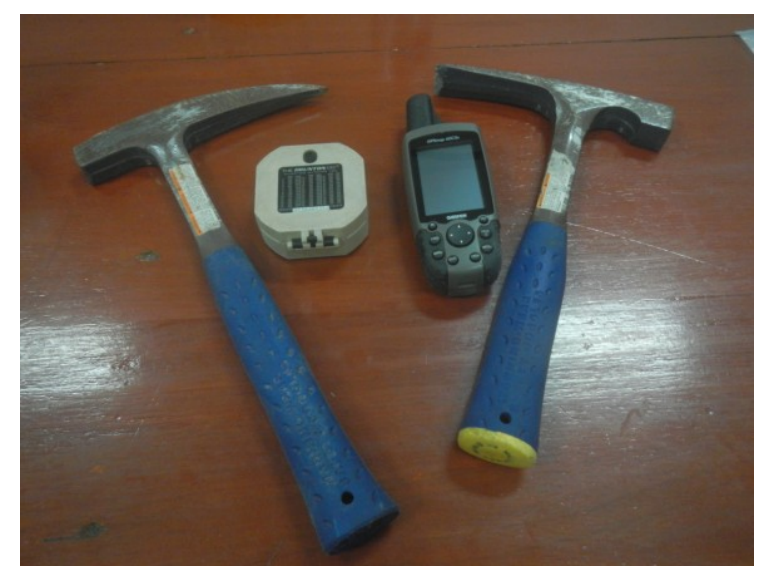


Gambar 1. Palu Gologi, Kompas, dan GPS

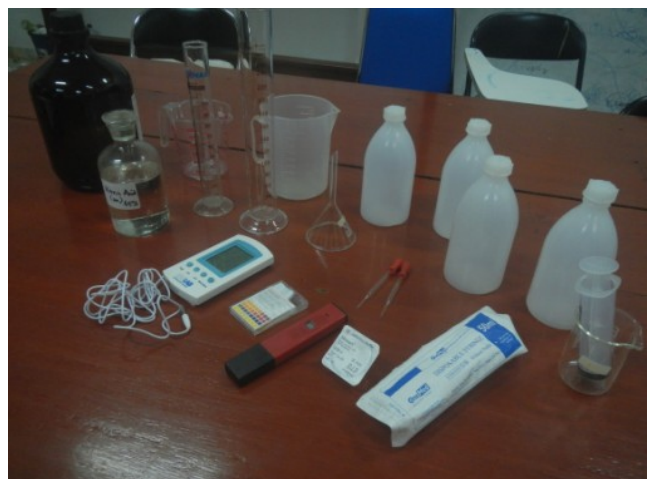

Gambar 2. Alat dan Bahan Pengambilan Sampel Fluida

\section{Metode Penelitian}

Survei lapangan merupakan salah satu cara yang digunakan untuk menentukan potensi sumber panasbumi. Selain itu survei lapangan dilakukan untuk mengkonfirmasi manifestasi panasbumi dan melakukan pengambilan sampel fluida panasbumi untuk dianalisa kandungan geokimianya. Pada saat survei lapangan selain mengambil sampel juga dilakukan pencatatan titik lokasi dengan GPS dan dokumentasi.

Cara pengambilan sampel fluida panasbumi adalah sebagai berikut:

1. Melakukan pengukuran sifat fisik fluida panasbumi berupa: $\mathrm{pH}$, debit, suhu fluida, dan suhu ambient.

2. Melakukan pengambilan sampel fluida panasbumi sebanyak $1000 \mathrm{ml}$ dengan syringe $50 \mathrm{ml}$ kemudian disaring dengan saringan berukuran $0,45 \mu \mathrm{m}$. Filtrat dibagi dua bagian masing-masing sebanyak $500 \mathrm{ml}$ dan ditempatkan dalam dua botol plastik PE. Sebelum digunakan kedua botol terlebih dahulu dibilas dengan fluida panasbumi yang sudah disaring sebanyak paling tidak dua kali.

3. Satu botol diberi tanda lokasi dan kode untuk analisa anion $(\mathrm{Cl}$, $\mathrm{HCO}_{3}, \mathrm{SO}_{4}, \mathrm{~F}$ ), penanda yang digunakan seperti pada Gambar 3.

4. Satu botol lainnya dilakukan pengasaman dengan $\mathrm{HNO}_{3}$ 1:1 hingga $\mathrm{pH}$ dibawah 3 sebagai bahan analisa kation dan kandungan silika. Botol diberi tanda lokasi dan kode untuk analisa kation ( $\mathrm{Na}, \mathrm{K}, \mathrm{Li}, \mathrm{Mg}, \mathrm{Ca}$, $\mathrm{Fe}, \mathrm{Al}, \mathrm{As}$ ) dan silika.

\begin{tabular}{|l|}
\hline \multicolumn{1}{|c|}{ Label Botol Sampel } \\
\hline Lokasi Manifestasi: \\
Mataair/Kolam/Nomor: \\
Tanggal: \\
Waktu: \\
Suhu $\left({ }^{\circ} \mathrm{C}\right):$ \\
pH: \\
disaring/tidak disaring* \\
diasamkan/tidak diasamkan* \\
Nomor Botol \\
*. Coret yang tidak perlu
\end{tabular}

Gambar 3. Contoh Label Botol

\section{Metoda Analisa}

Analisis anion, kation dan major element dan silika dilakukan di geokimia Pusat Sumber Daya Mineral Batubara dan Panas Bumi, Kementerian Energi Sumber Daya Mineral, Bandung dengan menggunakan metode titrimetri, flamefotometri, spektrofotometri dan Atomic Absorption Spectrofotometri (AAS), untuk mengetahui senyawa kimia terlarut dalam air

\section{Geothermometer}

Metode analisa disusun berurut dan dapat dilengkapi gambar atau rumus yang ditulis menggunakan equation dan diberi nomor: Geothermometer memungkinkan pendugaan suhu fluida di reservoir yang merupakan alat penting untuk mengevaluasi lapangan baru dan memonitor produksi suatu sistem hidrologi. Metode geothermometer yang digunakan pada penelitian ini berdasarkan pada kelarutan mineral silika dan reaksi pertukaran (Na-K, Na-K-Ca, dll.).

Silika geothermometer

$\mathrm{t}^{\circ} \mathrm{C}=(1522 /(5,75-\operatorname{logSiO} 2))-273$

$\mathrm{Na} / \mathrm{K}$ geothermometer

$t^{\circ} \mathrm{C}=933 /[\log (\mathrm{Na} / \mathrm{K})+0,993]-273$ 


\section{Potensi Panas Bumi}

Penentuan potensi panasbumi dinyatakan dalam MWe (megawatt ekuivalen).

$\mathrm{H}=\mathrm{A} \times \mathrm{Q}$

Dimana:

$\mathrm{H}$ : Besar sumber daya (MWe)

A : Luas daerah prospek $\left(\mathrm{km}^{2}\right)$

Q : Rapat Daya (MWe/km²)

Metode yang digunakan untuk penentuan $Q$ adalah parameter Volumetrik Lump yang ditulis kembali oleh Panitia Kecil Standardisasi Panas Bumi pada tahun 1994:

$Q=0,11585 \times A \times\left(T_{a g}-T_{c o}\right)$

Dimana:

$\mathrm{T}_{\mathrm{ag}}$ : Suhu geothermometer $\left({ }^{\circ} \mathrm{C}\right)$

$\mathrm{T}_{\mathrm{co}} \quad$ : Suhu cutt-off $\left({ }^{\circ} \mathrm{C}\right)$

Suhu cutt-off berdasarkan pada SNI 136009-1999.

\section{HASIL PENELITIAN DAN PEMBAHASAN}

\section{Hasil Penelitian}

Survei lapangan pada manifestasi panasbumi mata air panas Demini di Distrik Ransiki Kabupaten Manokwari Selatan Provinsi Papua Barat memberikan data fisik seperti pada Tabel 1.

Tabel 1. Sifat Fisik Fluida Mata Air Panas Demini

\begin{tabular}{|c|l|c|}
\hline No. & \multicolumn{1}{|c|}{ Sifat Fisik } & Besaran \\
\hline 1. & $\mathrm{pH}$ & 7,5 \\
\hline 2. & $\mathrm{~T}$ & $45^{\circ} \mathrm{C}$ \\
\hline 3. & Tambient & $28^{\circ} \mathrm{C}$ \\
\hline 4 & Debit & $7 \mathrm{~L} /$ menit \\
\hline
\end{tabular}

Sementara itu Tabel 2 menunjukkan senyawa kimia yang terdapat pada contoh fluida panasbumi dari air panas Demini. Senyawa fluida tersebut akan digunakan untuk pendugaan panas reservoir dan kemudian menentukan besaran potensi panasbumi.

\begin{tabular}{|c|l|c|}
\hline No. & Senyawa & Konsentrasi $(\mathrm{mg} / \mathrm{L})$ \\
\hline 1. & $\mathrm{SiO}_{2}$ & 21,49 \\
\hline 2. & $\mathrm{Na}$ & 30,6 \\
\hline 3. & $\mathrm{~K}$ & 0,22 \\
\hline 4. & $\mathrm{Ca}$ & 2,15 \\
\hline
\end{tabular}

Dari perhitungan geothemometer diperoleh panas sebesar $71,5{ }^{\circ} \mathrm{C}$ untuk metode perhitungan $\mathrm{SiO}_{2}$ dan $84{ }^{\circ} \mathrm{C}$ untuk metode perhitungan Na-K. Sementara itu potensi energi batuan berturut-turut sebesar 17 MWe dan 53,5 MWe untuk luas reservoir panasbumi sebesar $5 \mathrm{~km}^{2}$.

\section{Pembahasan}

Mata air panas Demini di Distrik Momiwaren, Kabupaten Manokwari Selatan Provinsi Papua Barat merupakan manifestasi panasbumi yang belum banyak diketahui bahkan oleh masyarakat di Kabupaten Manokwari Selatan. Lokasi manifestasi tersebut relatif dekat dengan jalan akses, namun demikian posisinya yang berada pada kaki pegunungan menyebabkan akses yang tersedia terbatas. Jarak dari jalan besar ke manifestasi panasbumi kurang lebih $3 \mathrm{~km}$, namun demikian dua kilometer terakhir hanya dapat ditempuh dengan motor trail (Gambar 4) dan dilanjutkan dengan jalan kaki.

Kondisi akses yang sulit dijangkau mengakibatkan kemungkinan untuk menjadikan sebagai objek wisata perlu banyak pembenahan. Selain itu lokasi yang terbatas luasannya dan cukup jauh dari daerah berpenduduk juga dapat menjadi hambatan bagi pengembangan potensi wisata mata airpanas Demini.

Dari komposisi geokimianya dapat digolongkan sebagai manifestasi panasbumi tepi, yang berarti manifestasi tersebut keluar jauh dari sumber primernya. Dari data lapangan, mata air panas Demini merupakan lokasi yang representatif sebagai tempat pengambilan sampel fluida panasbumi karena debit air yang besarnya diatas $1 \mathrm{~L} /$ menit mengakibatkan komponen-komponen geokimia tidak segera terendapkan. 


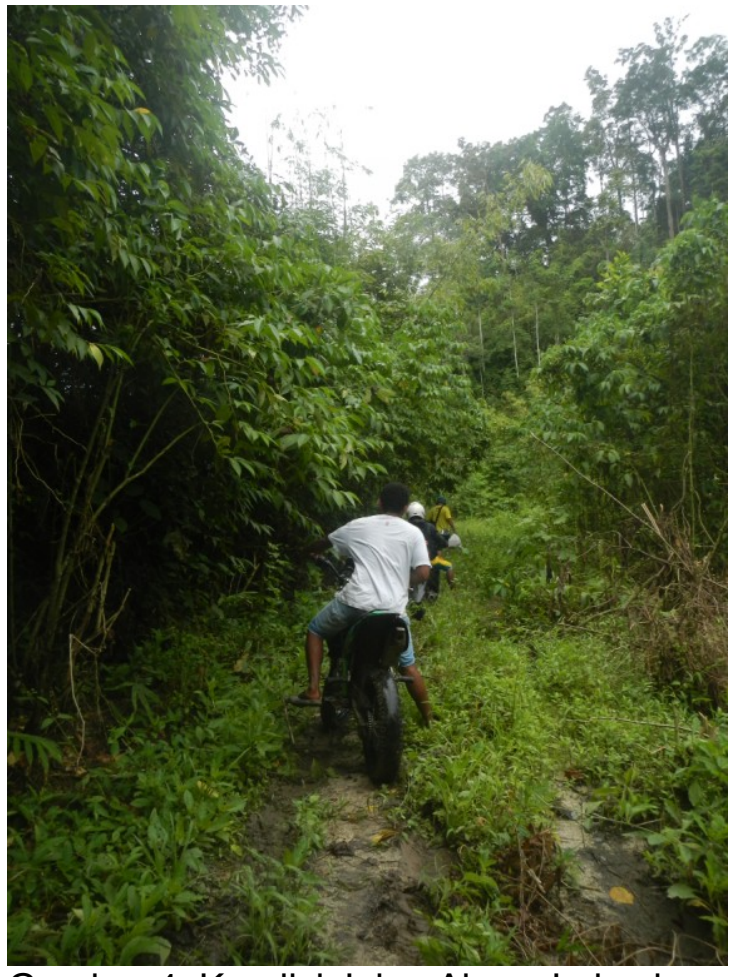

Gambar 4. Kondisi Jalan Akses Lokasi

Manifestasi Panasbumi

Kondisi $\mathrm{pH}$ mata air panas yang relatif netral menandakan kemungkinan aquifer mata air panas berupa air meteorik yang masuk ke dalam batuan dan keluar sebagai mata air panas Demini. Dari perhitungan didapatkan potensi energi batuan sebesar 17 dan 53,5 MWe. Namun demikian bukan semata-mata potensi energi batuannya tapi juga perlu diperhatikan jenis manifestasi panasbuminya.

Pendugaan suhu reservoir dengan metode geothermometer merupakan pendugaan yang biasa digunakan pada upaya eksplorasi panasbumi, terlebih mata air panas Demini dikategorikan sebagai manifestasi tepi sehingga untuk memperoleh suhu reservoir yang tepat diperlukan operasi pemboran. Sesuai dengan panduan dari Badan Akreditasi Nasional, manifestasi panasbumi dengan suhu lebih kecil dari $125^{\circ} \mathrm{C}$ digolongkan sebagai suhu rendah/entalpi rendah. Jenis manifestasi ini cukup sulit untuk dijadikan pembangkit listrik karena suhu yang relatif rendah, namun demikian pada kisaran suhu 70 - 850C mata air panas Demini masih memungkinkan untuk menjadi sumber pembangkit listrik dengan menggunakan pembangkit listrik sistem siklus biner (binary cycle) yang memanfaatkan fluida sekunder membantu mambangkitkan listrik. Tantangan yang mungkin dihadapi adalah penenentuan fluida sekunder yang sesuai dengan fluida panasbumi, perspektif masyarakat, dan pembiayaan.

\section{KESIMPULAN DAN SARAN}

\section{Kesimpulan}

Potensi mata air panas
Demini merupakan manifestasi
berkategori suhu rendah.

- $\quad$ Pemanfaatan sebagai sumber pembangkit listrik terkendala biaya, perspektif masyarakat, dan teknologi.

\section{Saran}

Perlu kajian lebih jauh, baik itu aspek sosaial-budaya maupun teknologi untuk meyakinkan stakeholder atas pentingnya potensi panasbumi di Kampung Demini, Distrik Momiwaren, Kabupaten Manokwari Selatan.

\section{DAFTAR PUSTAKA}

2009. Survei Pendahuluan Panas Bumi Manokwari (Ransiki), Provinsi Papua Barat. Pusat Sumber Daya Geologi ESDM, Bandung 1998.

Klasifikasi Potensi Energi Panas Bumi di Indonesia. Badan Standardisasi Nasional - BSN. Jakarta.

Chandraskharam, D. 2012. Low Enthalpy Geothermal Resources [Online]. Available:

http://dchandra.geosyndicate.com/ne ws/?p=224. 22 Februari 2017.

Chandraskharam, D, Bundschuh, J. 2008. Low-Enthalpy Geothermal Resources for Power Generation. CRC Press - Taylor \& Francis Group. London.

Maghiar, T, Antal, C. 2001. Power Generation From Low-Enthalpy Geothermal Resources. GHC Bulletin, June 2001, 3. Bucharest. 
Raharjo, A. 2016. Pembangkit Listrik Panasbumi Tipe Binary Cycle Sebagai Alternatif Pengelolaan SDA Berkelanjutan Di Provinsi Papua Barat. Prosiding Biodiversitas, Sains, dan Matematika Tahun 2016. Seminar Nasional Biodiversitas, Sains, dan Matematika UNIPA Tahun 2016. Halaman 197-202.

Raharjo, A. 2014. Potensi Pengembangan Pembangkit Listrik Panasbumi Suhu Rendah Di Kabupaten Manokwari Selatan. Prosiding Penelitian FMIPA UNIPA Tahun 2014. Seminar Penelitian FMIPA UNIPA Tahun 2014. Halaman $57-60$.

Suryantini. 2013. Current Status of Estimates and Classification of Geothermal Potential in Indonesia.

IGA Workshop on "Developing Best Practice for Geothermal Exploration and Resource / Reserve Classification". Germany: International Geology Association. Essen. 